\title{
Los antivirales no reducen la incidencia de la neuralgia postherpética
}

\author{
Antivirals do not reduce the incidence of postherpetic neuralgia
}

\section{Objetivos}

Evaluar la efectividad de los antivirales para prevenir la neuralgia postherpética (NPH), definida como la persistencia o recurrencia del dolor luego de 120 días de producida la erupción.

\section{Fuentes de datos}

Registro especializado del grupo Cochrane de enfermedades neuromusculares, CENTRAL, MEDLINE, EMBASE, LILACS, y Sistema de Recuperación Biomédica China (en inglés, Chinese Biomedical Retrieval System) hasta abril de 2013. Se verificaron referencias de estudios publicados para identificar nuevos trabajos y se contactó a los autores para solicitar datos adicionales. No hubo restricción de idioma.

\section{Selección de estudios y extracción de datos}

Se consideraron estudios controlados y aleatorizados (ECA) en los que se trató, dentro de las $72 \mathrm{~h}$ de la aparición del herpes zóster, a adultos con antivirales administrados vía oral para prevenir la NPH. En los estudios analizados se excluyeron pacientes inmunosuprimidos, embarazadas o mujeres en lactancia, pacientes con disfunción renal o hepática, en tratamiento con glucocorticoides sistémicos, oncológicos, o que presentaban lesiones costrosas al momento de alistarse. Asimismo se excluyeron estudios que presentaron un seguimiento corto o irregular,
Chen N, y col. Cochrane Database Syst Rev. 2014 Feb 6;(2):CD006866. cuyo grupo control no recibió placebo, o aquellos con texto o reporte incompleto o no disponible. Dos autores seleccionaron los estudios, evaluaron el riesgo de sesgo y analizaron los datos independientemente.

\section{Resultados principales}

Se obtuvieron seis ECA con 1.211 participantes. Cinco estudios evaluaron aciclovir y un estudio (419 participantes) evaluó famciclovir. Los resultados del metanálisis se resumen en la Tabla 1. Con cuatro estudios (692 participantes) además fue posible realizar un metaanálisis que demostró una reducción leve pero significativa en la incidencia de neuralgia herpética (la forma aguda de neuritis) en el grupo tratado con aciclovir al mes de la aparición de la erupción ( $R R$ 0,83; IC95\% 0,71 a 0,96; p=0,01). La mayoría de estos estudios no evaluaron los efectos en el dolor o la calidad de vida.

\section{Conclusiones}

Hay evidencia de alta calidad que indica que el aciclovir oral no reduce significativamente la incidencia de NPH. Los otros antivirales carecen de evidencia suficiente para determinar su efecto.

Fuente de financiamiento: Fuente de financiamiento: Departamento de Neurología, West China Hospital, China. Conflicto de interés: Ninguno.

Tabla 1. Efectividad del los antivirales en la reducción de la incidencia de neuralgia post-herpética.

\begin{tabular}{|c|c|c|c|c|}
\hline Resultado & RR (IC95\%) & Estudios & Participantes & Calidad de la evidencia \\
\hline \multicolumn{5}{|c|}{ Aciclovir versus placebo } \\
\hline NPH a los 6 meses & $1.05(0.87$ a 1.27$)$ & $2^{2,3}$ & 476 & Alta \\
\hline NPH a los 4 meses & $0,75(0,51$ a 1,11$)$ & $3^{1,3,4}$ & 609 & Alta \\
\hline Efectos adversos & $1,01(0,88$ a 1,15$)$ & $4^{1,2,3,4}$ & 709 & Alta \\
\hline \multicolumn{5}{|c|}{ Famciclovir versus placebo } \\
\hline NPH con 500 mg & $1,15(0,87$ a 1,52$)$ & \multirow[t]{2}{*}{$1^{6}$} & \multirow[t]{2}{*}{419} & \\
\hline NPH con 750 mg & $1,31(1,01$ a 1,71$)$ & & & \\
\hline Efectos adversos & \multicolumn{3}{|l|}{ Similar en ambos grupos } & \\
\hline
\end{tabular}

NPH: neuralgia post-herpética. RR: riesgo relativo. IC95\%: intervalo de confianza del 95\%.

\section{Comentario}

El herpes zóster presenta una incidencia del 1,2 al 3,4 cada 1.000 personas año. Su complicación más frecuente es el desarrollo de la $\mathrm{NPH}$, siendo la edad un factor de riesgo importante. Se plantea que el $40 \%$ de los individuos mayores de 50 y el $75 \%$ de los mayores de 75 años desarrollarán NPH después del herpes zoster ${ }^{1,2,3}$. Hasta el momento los tratamientos para el manejo del dolor son diversos, pero han mostrado ser parcial o totalmente ineficaces. Por este motivo se ha planteado la importancia de prevenir el desarrollo de la $\mathrm{NPH}$ mediante diferentes estrategias, como el uso de corticoides, que no han demostrado eficacia. Al momento se discute la utilización de la vacunación para el virus de herpes zóster en mayores de 60 años para la prevención de este cuadro. Si bien la evidencia es insuficiente hay ciertas instituciones ${ }^{4}$ que sugieren su utilización. Otra estrategia planteada fue el uso de antivirales ya que el dolor crónico reflejaría la infección activa. La revisión recientemente comentada es la primera actualización desde la revisión publicada en 2009 y la misma no encontró nuevos estudios.

\section{Conclusiones del comentador}

Si bien el aciclovir no es eficaz para prevenir el NPH, reduciría la duración e intensidad del dolor durante la infección aguda, siempre que se utilice en forma precoz. Queda pendiente evaluar si la intensidad del dolor en la NPH se ve reducida por el uso de antivirales y de esta forma la calidad de vida de los pacientes mejora. Dicha información sería interesante obtenerla dado que el dolor crónico muchas veces genera depresión, fatiga, insomnio y alteración de las actividades diarias con gran impacto en la calidad de vida.

María Teste. [Salud Comunitaria Trenque Lauquen. maryteste@gmail.com ]

Teste M. Los antivirales no reducen la incidencia de la neuralgia postherpética. Evid Act Pract Ambul 2018;21(2):45. Comentado de: Chen N, Li Q, Yang J, y col. Antiviral treatment for preventing postherpetic neuralgia. Cochrane Database Syst Rev. 2014 Feb 6;(2):CD006866. doi: 10.1002/14651858. CD006866.pub3. PMID: 24500927.

Referencias

1. Dworkin RH, y col. Proposed classification of herpes zoster pain. Lancet 1994;343(8913):1648.

2. Portenoy RK, y col. Acute herpetic and postherpetic neuralgia: clinical review and current management. Annals of Neurology 1986;20(6):651-64.

3. Lancaster T, y col. Primary care management of acute herpes zoster: systematic review of evidence from randomized controlled trials. British Journal of General Practice 1995;45(390):39-45

4. Craig M. Update on Recommendations for Use of Herpes Zoster Vaccine. Centers for Disease Control and Prevention 2014:63(33);729-731. 